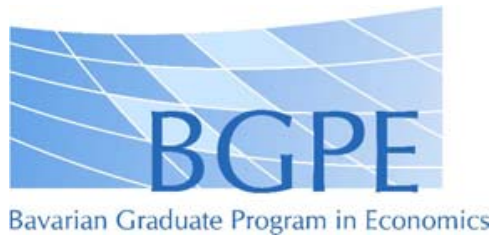

BGPE Discussion Paper

No. 10

\title{
Social Security with Rational and Hyperbolic Consumers
}

\author{
Hans Fehr \\ Christian Habermann \\ Fabian Kindermann
}

December 2006

ISSN 1863-5733

Editor: Prof. Regina T. Riphahn, Ph.D.

Friedrich-Alexander-University Erlangen-Nuremberg

(c) Hans Fehr, Christian Habermann, Fabian Kindermann 


\title{
Social Security with Rational and Hyperbolic Consumers*
}

\author{
Hans Fehr, Christian Habermann and Fabian Kindermann
}

December 2006

\begin{abstract}
The present paper studies the role of social security in an economy populated by overlapping generations of individuals that have time-consistent or time-inconsistent preferences, face mortality and individual income risk, borrowing constraints as well as progressive income taxes. Our simulations start from an artificial equilibrium where social security is completely neutral. Next we introduce successively alternative deviations from neutrality in order to isolate the various economic effects of social security. The latter are mainly the insurance provision against mortality and income risk, the negative liquidity effects for young households and the provision of a commitment technology for present-biased hyperbolic consumers. Our simulations indicate that the positive effects of social security dominate the negative ones for a wide range of parameter combinations. For our central parametrization social security induces an overall welfare gain which amounts to roughly 1.5 percent of aggregate resources in the hyperbolic model and a welfare loss of about 0.5 percent of resources in the model with rational consumers.
\end{abstract}

JEL Classification: H55, J26

Keywords: social security, stochastic general equilibrium, hyperbolic consumers

*Financial support from the Forschungsnetzwerk Alterssicherung (FNA) of the Deutsche Rentenversicherung Bund is gratefully acknowledged.

‡ Department of Economics, University of Wuerzburg, Sanderring 2, D-97070 Würzburg Fax: ++49-931-888-7129, E-Mail: hans.fehr@uni-wuerzburg.de 


\section{Introduction}

The efficiency consequences of pay-as-you-go financed social security are debated since a long time in the economic literature. Since the seminal article of Breyer (1989) it has been acknowledged that social security serves as a pure redistribution device across generations when all markets are perfect and labor supply is inelastic. This means that the elimination (or "privatization") of social security would generate no welfare gains for future generations as long as all existing old generations are fully compensated. On order to finance it's obligations the government would have to raise taxes and debt that exactly match the already existing implicit tax and debt burdens, see Geanakoplos et al. (1998) or Sinn (2000).

Matters are different when the central assumptions are relaxed. As Homburg (1990) or Breyer and Straub (1993) have shown, social security privatization could generate efficiency gains if labor supply is elastic and benefits are flat. When benefits are independent of former contributions, the pension system is progressive. Consequently, privatization is similar to a move from a progressive to a proportional labor income tax. Various simulation studies have quantified the labor market distortions and computed the resulting efficiency gains from privatization, see for example Feldstein (1998). However, as demonstrated by Fenge (1995), the unfunded pension system is Pareto-efficient even with elastic labor supply, if benefits are perfectly linked to former contributions. In this case the tax-like proportion of annual contributions is the same for all members of a cohort so that an equivalent explicit tax is needed to finance the (implicit) public debt inherited from the liquidated public system. This has two consequences. First, if the unfunded pension system is intragenerational fair, the labor-leisure distortion cannot be reduced by privatization as long as the tax structure is not altered. Second, improving (reducing) the link between benefits and contributions increases (reduces) economic efficiency, see for example Kotlikoff (1996) or Fehr (2000).

Up to now the discussion has abstracted from market imperfections. If the latter are taken into account, efficiency gains (or losses) from social security privatization are possible, if the pension system increases (or reduces) the extent of market failure. For example, Demmel and Keuschnigg (2000) demonstrate that the pension system increases labor market imperfections and, consequently, a debt-financed Pareto-improving transition to a funded system is possible. Corneo and Marquardt (2000) reach a similar conclusion in a model with unemployment and endogenous growth. Hubbard and Judd (1987) point out the role of social security with realistic capital market imperfections. Since it provides an insurance against lifespan uncertainty, social security reduces the inefficiencies due to the 
market failure in the private provision of annuities. On the other hand, in the presence of borrowing constraints social security will further increase the market failure so that privatization induces additional efficiency gains.

Another direction of research has explored the role of social security in providing an insurance against income uncertainty. İmrohoroğlu et al. (1995) develop a general equilibrium model with overlapping generations with individuals facing mortality and income risk. Private credit and annuity markets are closed by assumption. Agents supply labor inelastically when they are given the opportunity to work, otherwise they receive unemployment benefits. After the mandatory retirement age, individuals rely on flat-rate pension benefits. In this framework, social security provides an insurance against income risk and lifespan uncertainty and increases the existing liquidity constraints of young individuals. However, in the initial equilibrium (without social security) the growth rate of the economy exceeds the interest rate. Consequently, it is not surprising that the introduction of social security increases the resources of all generations. İmrohoroğlu et al. (1999) eliminate dynamic inefficiency by incorporating land as a fixed factor of production. In this setting, the introduction of social security has again positiv insurance and negative liquidity effects, but it also redistributes income across generations. While it turns out that the long-run equilibrium without social security is optimal, the result might be due to pure redistribution effects. On the other hand, Fuster et al. (2003) find that social security increases steady-state welfare for most households if two-sided altruism is taken into account. In this framework, the intergenerational redistribution induced by social security is (at least partly) neutralized by intervivos transfers and bequests. In addition, borrowing constraints are less binding so that social security mainly provides an insurance against uninsurable "labor ability" shocks at birth. A final argument in favor of social security is explored by İmrohoroğlu et al. (2003). Introducing quasi-hyperbolic discounting in the above framework, they show that social security may raise long-run welfare for individuals with time-inconsistent preferences if the short-term discount rate is sufficiently high. Therefore, social security may serve as a commitment device for individuals who do not adequately save for their retirement.

All studies with stochastic economies discussed so far share a common deficiency. Since they only consider the long-run effects of social security, the consequences for transitional generations are completely neglected. Therefore, the computed long-run welfare changes could be simply due to intergenerational redistribution. In order to provide a complete assessment of social security, one has to compute the transition path between steady states and separate intergenerational distribution from efficiency effects. Consequently, Huang et al. (1997) compare two experiments where the existing unfunded social security system 
is eliminated and a private or a mandatory state-run funded system is introduced with all existing and transitional generations compensated virtually. While both experiments yield a significant aggregate efficiency gain, the government-run funding scheme is preferred to privatization due to its superior insurance properties. Conesa and Krueger (1999) extend the Huang et al. (1997) framework by including variable labor supply. They simulate an immediate, a gradual and an announced elimination of social security and compute the political support for the three proposals in the initial year. Although for all cases considered agents would prefer to be born into the final steady-state, no proposal receives an initial voting majority in the closed economy case. The political support is declining when intra-cohort heterogeneity is increasing due to the rising insurance gains from flat pensions. While Conessa and Krueger (1999) can explain why pension reforms are delayed in democratic systems, their study does not include efficiency calculations. If many individuals receive small welfare losses while the (fewer) winners receive enormous welfare gains it might be possible that the reform receives no political support although it delivers aggregate efficiency gains. A very similar problem arises in Fuster et al. (2006) who extend their two-sided altruism model by incorporating variable labor supply and the transition paths across steady states. As before the family insurance substitutes the missing market insurance but now the social security contributions distort the labor supply choice. The latter is reinforced by the fact that the payroll tax comes on top of personal income taxes. Consequently, they find that the majority of individuals are better off with the elimination of social security in all privatization schemes considered. However, since the resulting welfare changes are not aggregated across individuals and generations, the overall efficiency effect is not explicitly determined.

The latter is done by Nishiyama and Smetters (2005a) who simulate a stylized 50-percent privatization of the US social security system. Again, the considered reform reduces the labor supply distortions but also the insurance provision of the social security system. In order to isolate the overall efficiency effects, the authors follow Auerbach and Kotlikoff (1987) by introducing a Lump-Sum Redistribution Authority (LSRA) which compensates initial agents and distributes the accumulated assets (i.e. efficiency gains) or debt (i.e. efficiency losses) to newborn and future agents. They find substantial efficiency gains from privatization, if wage shocks could be insured privately. Consequently, if income uncertainty is perfectly insured, the aggregate efficiency effect of social security is dominated by the distortions of the labor/leisure choice. However, if wage income shocks could not be insured, the overall efficiency effect from privatization is negative. This clearly indicates that the (positive) insurance effects of the US social security system dominate the distortionary effects on labor supply. Fehr and Habermann (2005) reach a 
similar conclusion for the German social security system. In contrast to the US system, benefits in the German system are strongly linked to former contributions. On the one hand, this institutional feature minimizes labor supply distortions but at the same time it also reduces the insurance provision against income shocks. Our simulations show that a more progressive system would yield a significant aggregate efficiency again, if all initial generations are compensated by LSRA transfers.

The current study directly supplements our previous one. However, instead of varying it's progressivity, we privatize the social security system and finance the existing social security claims by a mixture of debt and labor taxation. In order to isolate self-control problems, we compare economies populated either by rational or hyperbolic individuals. In contrast to previous studies, we separate and quantify the insurance, liquidity and labor supply effects implied by social security. Consequently, we compute our model with and without income uncertainty and start our analysis from artificial equilibria, where social security is completely neutral. Then we introduce successively alternative assumptions that advance our model closer to reality and allow to separate the effects that are at work. Our simulation results indicate that the German social security system clearly enhances aggregate efficiency if the economy is populated by hyperbolic consumers. The results are mixed with rational consumers. Here, social security increases efficiency with proportional taxes, but decreases efficiency with progressive taxes.

The next section, discusses how we model preferences as well as the tax and benefit system. Section 3 explains the calibration and simulation approach. Finally, section 4 presents the simulation results and section 5 offers some concluding remarks.

\section{The model economy}

\subsection{Demographics and intracohort heterogeneity}

We consider an economy populated by overlapping generations of individuals which may live up to a maximum possible lifespan of $J$ periods. At each date, a new generation is born where we have normalized its size $N_{1}=1$, i.e. we assume zero population growth. Individuals might face lifespan uncertainty with $\psi_{j} \leq 1$ the time-invariant conditional survival probability from age $j-1$ to age $j$, i.e. $N_{j}=\psi_{j} N_{j-1}$ and $\psi_{J+1}=0$.

Our model is solved recursively. Consequently, an agent faces the state vector $z_{j}=$ $\left(j, \mathrm{a}_{j}, e p_{j}, e_{j}\right)$ where $j \in \mathcal{J}=\{1, \ldots, J\}$ is the household's age, $\mathrm{a}_{j} \in A=\left[a^{\text {min }}, a^{\text {max }}\right]$ denotes assets held at the beginning of age $j, e p_{j} \in P=\left[e p^{\min }, e p^{\max }\right]$ defines the agent's accumulated earning points for public pension claims and $e_{j} \in E_{j}=\left[e_{j}^{\min }, e_{j}^{\max }\right]$ is the 
individual productivity at age $j$.

We distinguish environments with and without individual earnings uncertainty. In the case with certain income, we assume only one age-productivity profile so that there exists one representative agent for each cohort, i.e. $e_{j}^{\min }=e_{j}^{\max }$ for all $j \in \mathcal{J}$. With uncertain income the productivity state is assumed to follow a first-order Markov process described in more detail below. Consequently, each age- $j$ cohort is fragmented into subgroups $\xi\left(z_{j}\right)$, according to the initial distribution $(j=1)$, the Markov process and optimal decisions $(j>1)$. Let $X\left(z_{j}\right)$ be the corresponding cumulated measure to $\xi\left(z_{j}\right)$. Hence,

$$
\int_{A \times P \times E_{j}} d X\left(z_{j}\right)=1 \text { for all } j=1, \ldots, J
$$

must hold, as $\xi\left(z_{j}\right)$ is not affected by cohort sizes but only gives densities within cohorts. In the following, we concentrate on the long run equilibrium and omit the time index $t$ and the state index $z_{j}$ for every variable whenever possible. Agents are then only distinguished according to their age $j$.

\subsection{Budget constraints and bequests}

The budget constraint is defined as follows:

$$
\mathrm{a}_{j+1}=\mathrm{a}_{j}(1+r)+w_{j}\left(1-\tau_{j}\right)+p_{j}-T\left(y_{j}\right)-\left(1+\tau_{c}\right) c_{j}+b_{j} \quad \mathrm{a}_{j} \geq \underline{\mathrm{a}} \forall j .
$$

with $\mathrm{a}_{1}=\mathrm{a}_{J+1}=0$. In addition to interest income from savings $r \mathrm{a}_{j}$, households receive gross labor income $w_{j}=w\left(1-\ell_{j}\right) e_{j}$ during their working period as well as public pensions $p_{j}$ during retirement. As time endowment is normalized to one, $\ell_{j}$ defines leisure consumption and $w$ the wage rate for effective labor. They have to pay income taxes $T\left(y_{j}\right)$ which depend on taxable income $y_{j}$ and the tax schedule $T(\cdot)$. Due to a contribution ceiling the pension contribution rate $\tau_{j}$ depends on income. The price of consumption goods $c_{j}$ includes consumption taxes $\tau_{c}$ and $b_{j}$ defines the accidental bequests received at age $j$. Finally, assets might be restricted to a specific floor $\underline{\text { a. }}$

Our model abstracts from annuity markets. Consequently, private assets of all agents who died are aggregated and then distributed among all working age cohorts following an exogenous age- and productivity-dependent distribution scheme $\Gamma\left(j, e_{j}\right)$, i.e.

$$
b_{j}=\Gamma\left(j, e_{j}\right) \sum_{i=1}^{J}\left(1-\psi_{i+1}\right) N_{i} \int_{A \times P \times E_{j}}(1+r) \mathrm{a}_{i+1}\left(z_{i}\right) d X\left(z_{i}\right) \quad \text { for all } \quad j=1, \ldots, J
$$


The age distribution of bequests is computed in the initial steady state where we assume that the heirs always receive the assets of the generation which was 25 years older ${ }^{1}$. In order to reflect empirical evidence and to highlight their stochastic nature, we assume that bequests are distributed within a generation proportional to the current productivity level $e_{j}$

\subsection{Individual preferences and consumer welfare}

Our model assumes a preference structure that is represented by a time-separable, nested CES utility function. In order to isolate risk aversion from intertemporal substitution, we follow the approach of Epstein and Zin (1991) and formulate the maximization problem of a representative consumer recursively.

We distinguish between rational and hyperbolic consumers. The former exhibit timeconsistent preferences and consequently do not regret their previous decisions in the future. Following the seminal work of Strotz (1956), we model the decision problem of a hyperbolic consumer as an intrapersonal game between a sequence of "selves" with conflicting preferences. Taking the strategies of his future selves as given the current self picks a strategy that is optimal from his own perspective.

The consumer at age $j$ and state $z_{j}$ first has to forecast his future actions. His future self (who is at age $j+1$ ) will maximize the objective function

$$
\max _{\hat{c}_{j+1}, \hat{\ell}_{j+1}}\left\{u\left(\hat{c}_{j+1}, \hat{\ell}_{j+1}\right)^{1-\frac{1}{\gamma}}+\hat{\beta} \delta \psi_{j+2} E\left[\hat{V}\left(z_{j+2}\right)\right]^{1-\frac{1}{\gamma}}\right\}^{\frac{1}{1-\frac{1}{\gamma}}}
$$

by choosing consumption and leisure. If lifespan is uncertain, the expected utility in future periods is discounted with $\delta$ and weighted with the survival probability $\psi_{j+2}$. The literature distinguishes between so called "naive" and "sophisticated" hyperbolic consumers, see O'Donoghue and Rabin (1999). The former think that their future selves will behave in a time-consistent manner despite the fact that they have consistently violated this belief in the past, i.e. $\hat{\beta}=1$. The latter correctly foresee that their future selves will also behave in a time-inconsistent way, i.e. $\hat{\beta}=\beta$ where $\beta$ defines the discount rate of the current selves $^{2}$. Consequently, $\hat{c}_{j+1}$ and $\hat{\ell}_{j+1}$ denote the believe of the current self about his future actions. The expectation operator $E$ in (3) indicates that future utilities are computed

\footnotetext{
${ }^{1}$ If heirs would be younger than 20, then heirs are age-group 20-24 and similar if heirs would be older than $j_{R-1}$, then heirs are $j_{R-1}$.

${ }^{2}$ Of course, it would be no problem to consider also intermediate cases where $\hat{\beta} \in(\beta, 1)$.
} 
over the distribution of $e_{j+2}$, i.e.

$$
E\left[\hat{V}\left(z_{j+2}\right)\right]=\left[\int_{E_{j}} \pi_{j+1}\left(e_{j+2} \mid e_{j+1}\right) \hat{V}\left(z_{j+2}\right)^{1-\eta} d e_{j+2}\right]^{\frac{1}{1-\eta}}
$$

where $\pi_{j+1}(\cdot)$ denotes the age-dependent probability at age $j+1$ to experience productivity $e_{j+2}$ in the next period if the current productivity is $e_{j+1}$. The parameters $\gamma$ and $\eta$ define the intertemporal elasticity of substitution between consumption and leisure in different years and the degree of (relative) risk aversion. Note that for the special case $\eta=\frac{1}{\gamma}$ we are back at the traditional expected utility specification, see Epstein and Zin (1991, 266). The value function $\hat{V}(\cdot)$ for future beliefs (with $\hat{c}_{j}$ and $\hat{\ell}_{j}$ from $(3)$ ) is computed for any age $j=2, \ldots, J$ from

$$
\hat{V}\left(z_{j}\right)=\left\{u\left(\hat{c}_{j}, \hat{\ell}_{j}\right)^{1-\frac{1}{\gamma}}+\delta \psi_{j+1} E\left[\hat{V}\left(z_{j+1}\right)\right]^{1-\frac{1}{\gamma}}\right\}^{\frac{1}{1-\frac{1}{\gamma}}}
$$

The current self at age $j$ maximizes the objective function

$$
\max _{c_{j}, \ell_{j}}\left\{u\left(c_{j}, \ell_{j}\right)^{1-\frac{1}{\gamma}}+\beta \delta \psi_{j+1} E\left[\hat{V}\left(z_{j+1}\right)\right]^{1-\frac{1}{\gamma}}\right\}^{\frac{1}{1-\frac{1}{\gamma}}}
$$

subject to the budget constraint (1) and $\mathrm{a}_{j} \geq \underline{\mathrm{a}}$ and given his believes $E[\hat{V}]$ about the behavior of his future selves. Note that the decision functions $c_{j}\left(z_{j}\right)$ and $\ell_{j}\left(z_{j}\right)$ denote the actual behavior of the agent. The latter are also used to compute the welfare of the agent, i.e.

$$
V\left(z_{j}\right)=\left\{u\left(c_{j}, \ell_{j}\right)^{1-\frac{1}{\gamma}}+\delta \psi_{j+1} E\left[V\left(z_{j+1}\right)\right]^{1-\frac{1}{\gamma}}\right\}^{\frac{1}{1-\frac{1}{\gamma}}} .
$$

The time-inconsistency in preferences is evident from the fact that the $\beta, \hat{\beta}$ terms appear in the decision problems (3) and (5) but not in the calculation of the value functions (4) and (6). It should also be clear that for $\beta=\hat{\beta}$ the decision and value functions of the beliefs $\hat{c}_{j}, \hat{\ell}_{j}$ and $\hat{V}$ and the respective functions of the actual behavior $c_{j}, \ell_{j}$ and $V$ coincide. Consequently, sophisticated hyperbolic consumers (where $\beta=\hat{\beta}<1$ ) behave differently compared to time-consistent consumers (i.e. where $\beta=\hat{\beta}=1$ ) but the solution algorithm is quite similar. For naive hyperbolic consumers (i.e. where $\beta<1$ and $\hat{\beta}=1$ ) the decision function and the respective value functions of current and future selves do not coincide so that the computational algorithm has to be specified differently. In the following we only report the results with naive hyperbolic consumers, since for our calibration the results with sophisticated hyperbolic consumers were very similar ${ }^{3}$.

\footnotetext{
${ }^{3}$ Of course, simulation results with sophisticated consumers are available upon request.
} 
The period utility function is defined by

$$
u\left(c_{j}, \ell_{j}\right)=\left[\left(c_{j}\right)^{1-\frac{1}{\rho}}+\alpha\left(\ell_{j}\right)^{1-\frac{1}{\rho}}\right]^{\frac{1}{1-\frac{1}{\rho}}}
$$

where $\rho$ denotes the intratemporal elasticity of substitution between consumption and leisure at each age $j$, while $\alpha$ defines the age-independent leisure preference parameter.

\subsection{The production side}

Firms in this economy use capital and labor to produce a single good according to the Cobb-Douglas production technology $Y=\varrho K^{\varepsilon} L^{1-\varepsilon}$ where $Y, K$ and $L$ are aggregate output, capital and labor, $\varepsilon$ is capital's share in production, and $\varrho$ defines a technology parameter. Capital depreciates at a constant rate $\delta_{k}$ and firms have to pay corporate taxes $T_{k}=\tau_{k}\left[Y-w L-\delta_{k} K\right]$ where the corporate tax rate $\tau_{k}$ is applied to the output net of labor costs and depreciation. Firms maximize profits renting capital and hiring labor from the households so that marginal products equal $r$ the interest rate for capital and $w$ the wage rate for effective labor.

\subsection{The government sector}

Our model distinguishes between the tax system and the pension system. In each period the government issues new debt $\Delta B$ and collects taxes from households and firms in order to finance general government expenditures $G$ as well as interest payments on its debt. We assume that public debt to output ratio is 60 percent in the benchmark case. General government expenditures $G$ consist of government purchases of goods and services which are fixed per capita. Revenues of income taxation equal:

$$
T_{y}=\sum_{j=1}^{J} N_{j} \int_{A \times P \times E_{j}} T\left(y_{j}\left(z_{j}\right)\right) d X\left(z_{j}\right) .
$$

In the initial long run equilibrium we set $\tau_{c}$ exogenous and compute $G$ endogenous from

$$
G=T_{y}+T_{k}+\tau_{c} C-r B_{G}
$$

where $C$ defines aggregate consumption (see (17)).

We assume that contributions to public pensions are exempted from tax while the benefits are fully taxed. Consequently, taxable gross income $y_{j}$ is computed from gross labor income net of pension contributions and a fixed work related allowance $d_{w}$, nominal ${ }^{4}$

\footnotetext{
${ }^{4}$ In order to reflect realistic features of capital income taxation in a model without inflation, we assume for taxation purposes a nominal interest rate $\hat{r}$, i.e. real interest rate $r$ plus a fictive inflation. The latter exacerbates the distortions of real capital income taxation, see Feldstein (1997).
} 
capital income net of a saving allowance $d_{s}$ and - after retirement - public pensions.

$$
y_{j}=\max \left[w_{j}\left(1-\tau_{j}\right)-d_{w} ; 0\right]+\max \left[\hat{r} \mathrm{a}_{j}-d_{s} ; 0\right]+p_{j}
$$

Given taxable income, we either apply a proportional tax rate $\left(\bar{\tau} y_{j}\right)$ or the progressive tax code of 2005 in Germany [T05 $\left.\left(y_{j}\right)\right]$.

In each year, the pension system pays old-age benefits and collects payroll contributions from wage income below the contribution ceiling which is fixed at two times the average income $\bar{w}$. Individual pension benefits $p_{j}$ of a retiree of age $j \geq j_{R}$ in a specific year are computed from the product of his earning points $e p_{j_{R}}$ the retiree has accumulated at retirement and the actual pension amount $(A P A)$ of the respective year:

$$
p_{j}=e p_{j_{R}} \times A P A .
$$

The accumulated earning points depend on the relative income position $\min \left[w_{j} / \bar{w} ; 2\right]$ of the worker at working age $j<j_{R}$. Since the contribution ceiling is fixed at the double of average income $\bar{w}$, the maximum earning points that could be collected per year are 2 . Accumulated earning points at age $j$ are therefore

$$
e p_{j+1}=e p_{j}(1+\bar{r})+\min \left[w_{j} / \bar{w} ; 2\right] \cdot \mu(\bar{r})
$$

where $\bar{r}$ denotes an "internal interest factor" for accumulated earning points and $e p_{1}=0$. In order to keep the pension level constant, we reduce the initial level of earning points received proportionally whenever we consider $\bar{r}>0$, i.e. $\mu(0)=1, \mu^{\prime}(\bar{r})<0^{5}$.

The budget of the pension system must be balanced in the long run. The aggregated pension benefits and contributions tax base are

$$
\begin{aligned}
P B & =\sum_{j=j_{R}}^{J} N_{j} \int_{A \times P \times E_{j}} p_{j}\left(z_{j}\right) d X\left(z_{j}\right) \\
P C & =\sum_{j=1}^{j_{R}-1} N_{j} \int_{A \times P \times E_{j}} \min \left[w_{j}\left(z_{j}\right) ; 2 \bar{w}\right] d X\left(z_{j}\right) .
\end{aligned}
$$

Households don't pay contribution on income above the contribution ceiling. The general contribution rate $\tau$ is computed as follows

$$
\tau=\frac{P B}{P C}
$$

\footnotetext{
${ }^{5}$ More specifically, we compute $\mu(\bar{r})=\left(j_{R}-1\right) /\left(\sum_{i=1}^{j_{R}-1}(1+\bar{r})^{j_{R}-1-i}\right)$.
} 
Note that the general social security contribution rate $\tau$ which is calculated from (12) is not necessarily identical with the individual contribution rates in the budget constraint (1). The latter is given by

$$
\tau_{j}= \begin{cases}\tau & \text { if } \quad w_{j} \leq 2 \bar{w} \\ \tau 2 \bar{w} / w_{j} & \text { if } \quad w_{j}>2 \bar{w}\end{cases}
$$

\subsection{Equilibrium and the computational method}

Given the fiscal policy $\left\{G, B_{G}, \tau_{k}, T(y), \tau_{c}, \tau\right\}$, a stationary recursive equilibrium is a set of value functions $\left\{V\left(z_{j}\right)\right\}_{j=1}^{J}$, household decision rules $\left\{c_{j}\left(z_{j}\right), \ell_{j}\left(z_{j}\right)\right\}_{j=1}^{J}$, distribution of unintended bequest $\left\{b\left(z_{j}\right)\right\}_{j=1}^{J}$, time-invariant measures of households $\left\{\xi\left(z_{j}\right)\right\}_{j=1}^{J}$, relative prices of labor and capital $\{w, r\}$ such that the following conditions are satisfied:

1. given fiscal policy, factor prices and bequests, households' decision rules solve the households decision problem (5);

2. factor prices are competitive, i.e.

$$
\begin{aligned}
& w=(1-\varepsilon) \varrho\left(\frac{K}{L}\right)^{\varepsilon} \\
& r=\left(1-\tau_{k}\right)\left[\varepsilon \varrho\left(\frac{L}{K}\right)^{1-\varepsilon}-\delta_{k}\right]
\end{aligned}
$$

3. in the closed economy aggregation holds,

$$
\begin{aligned}
L & =\sum_{j} N_{j} \int_{A \times P \times E_{j}}\left(1-\ell\left(z_{j}\right)\right) e_{j} d X\left(z_{j}\right) \\
C & =\sum_{j} N_{j} \int_{A \times P \times E_{j}} c_{j}\left(z_{j}\right) d X\left(z_{j}\right) \\
K & =\sum_{j} N_{j} \int_{A \times P \times E_{j}} a_{j} d X\left(z_{j}\right)-B_{G}
\end{aligned}
$$

while in the small open economy aggregate capital is derived from (15);

4. Let $\mathbf{1}_{h=x}$ be an indicator function that returns 1 if $h=x$ and 0 if $h \neq x$. Then, the law of motion of the measure of households is, for $j \in \mathcal{J}$,

$$
\xi\left(z_{j+1}\right)=\int_{A \times P \times E_{j}} \mathbf{1}_{a_{j+1}=a_{j+1}\left(z_{j}\right)} \times \mathbf{1}_{e p_{j+1}=e p_{j+1}\left(z_{j}\right)} \pi_{j}\left(e_{j+1}, e_{j}\right) d X\left(z_{j}\right) .
$$


5. unintended bequest satisfy

$$
\sum_{j=1}^{j_{R}-1} N_{j} \int_{A \times P \times E_{j}} b_{j}\left(z_{j}\right) d X\left(z_{j}\right)=\sum_{i=1}^{J}\left(1-\psi_{i+1}\right) N_{i} \int_{A \times P \times E_{j}}(1+r) \mathrm{a}_{i+1}\left(z_{i}\right) d X\left(z_{i}\right) .
$$

6. the government budget (8) as well as the budget of the pension system (12) are balanced intertemporally;

7. the goods market clears, i.e.

$$
\begin{array}{cc}
Y=C+\delta_{k} K+G & \text { (closed economy) } \\
Y=C+\delta_{k} K+G+N X & \text { (open economy) }
\end{array}
$$

with $N X$ as net exports.

The computation method follows the Gauss-Seidel procedure of Auerbach and Kotlikoff (1987). For the initial steady state which reflects the current German social security system described above we start with a guess for aggregate variables, bequests distribution and exogenous policy parameters. Then we compute the factor prices and the individual decision rules and value functions. The latter involves the discretization of the state space which is explained in the appendix. Next we obtain the distribution of households and aggregate assets, labor supply and consumption as well as the social security tax rate and the consumption tax rate that balances government budgets. This information allows us to update the initial guesses. The procedure is repeated until the initial guesses and the resulting values for capital, labor, bequests and endogenous taxes have sufficiently converged.

Next we solve for the transition path where social security is completely eliminated. We assume that the transition between the initial and the final steady state takes $4 \times J$ periods. With alternative policy parameters we assume in the first guess that aggregate values and bequests of the initial equilibrium would remain constant along the transition. Then we update for each period of the transition the individual and aggregate variables until we reach convergence.

\section{Calibration of the initial equilibrium}

In order to reduce computational time, each model period covers five years. Agents start life at age $20(j=1)$, are forced to retire at age $60\left(j_{R}=9\right)$ and face a maximum 
possible life span of 100 years $(J=16)$. The conditional survival probabilities $\psi_{j}$ are computed from the year 2000 Life Tables reported in Bomsdorf (2003). With respect to the preference parameters we set the intertemporal elasticity of substitution $\gamma$ to 0.5 , the intratemporal elasticity of substitution $\rho$ to 0.6 , and the leisure preference parameter $\alpha$ to 1.5. This is within the range of commonly used values, see Auerbach and Kotlikoff $(1987,52 \mathrm{f}$.) or Fehr $(1999,57)$. In addition, the implied compensated wage elasticity of labor supply is 0.34 in our benchmark, which is in line with the results of Fenge et al. (2006). The coefficient of relative risk aversion $\eta$ is set at 4.0 in the benchmark. Values between 1 and 5 for $\eta$ are typically perceived as reasonable in the literature, see Cecchetti et al. $(2000,792)$ for a discussion. Finally, with respect to the time preference rates $\beta$ and $\delta$ we distinguish two combinations which both yield a realistic wealth to income ratio. Following Angeletos et al. $(2001,54)$ we assume that the rational consumer (i.e. $\beta=1$ ) has a lower discount factor $\delta$ than the hyperbolic consumer. In order to calibrate a realistic capital to output ratio, the discount factor for the rational consumer is set at 0.9 which implies an annual discount rate of about 2 percent. Next we specify for the hyperbolic consumer $\beta=0.75$. In order to calibrate the same capital to output ratio we have to assume $\delta=1.0$. Angeletos et al. $(2001,54)$ report that $\beta=0.7$ is typically measured in laboratory experiments. While they also assume higher annual discount rates, the reported difference between the hyperbolic and rational consumer is quite similar. Figure 1 compares the discount functions and also includes a strong hyperbolic case which is used in the sensitivity analysis.

Figure 1: Discount functions of exponential and hyperbolic consumers

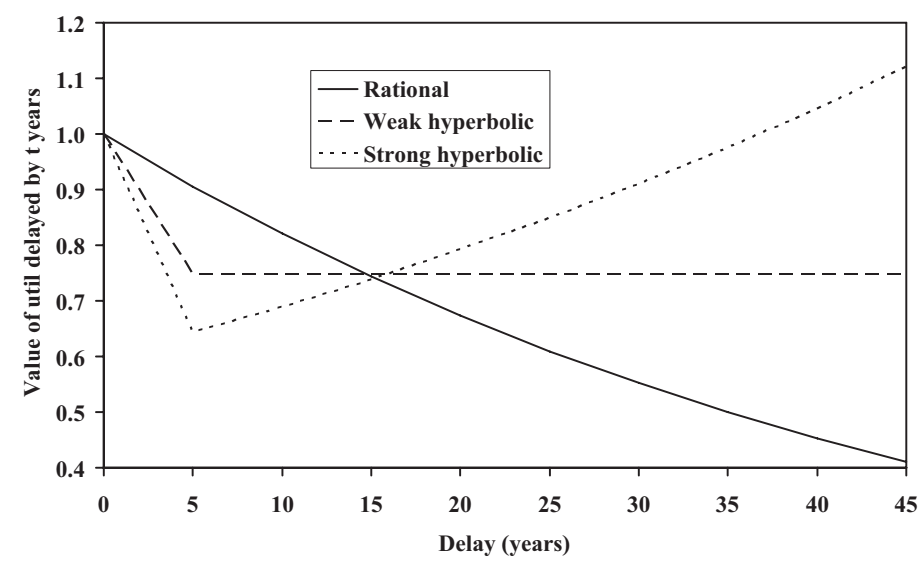

With respect to technology parameters we chose the general factor productivity $\varrho=1.5$ in order to normalize labor income and set the capital share in production $\varepsilon$ at 0.3 . The annual depreciation rate for capital is set at $\delta_{k}=0.06$. The actual pension amount 
$(A P A)$ in equation (10) is computed in order to yield a standard pension (i.e. where $\left.e p_{j_{R}}=j_{R}-1\right)$ which amounts to 60 percent of net average earnings $\bar{w}_{n}$. This procedure yields a realistic contribution rate for Germany. As already explained, the taxation of gross income (from labor, capital and pensions) is close to the current German income tax code and the marginal tax rate schedule introduced in 2005 (including solidarity tax). Consequently, after the basic allowance of $7800 €$ the marginal tax rate rises linearly from 15.8 to maximum of 44.3 percent when taxable income $y_{j}$ passes $52.000 €$. We assume that our individuals are married couples with a sole wage earner and apply the German income splitting method. There exists a special allowance for labor income of $d_{w}=1200$ $€$ while for capital income the special allowance amounts to $d_{s}=3600 €(\text { per couple })^{6}$. Finally, the corporate tax rate is set at $\tau_{k}=0.15$.

In order to model the income process, we distinguish six productivity profiles across the life cycle. Fehr (1999) has estimated five such profiles from data of the German SocioEconomic Panel Study (SOEP). We split up the profile of the lowest income class in order to improve the income distribution. When an agent enters the labor market (at age 20-24) he belongs to the lowest productivity level with a probability of 10 percent, to the second lowest again with 10 percent and to higher levels with 20 percent, respectively. After the initial period, agents change their productivity levels according to the age-specific Markov transition matrices which are reported in the appendix. The latter are computed also from SOEP data for different years between 1984 and 2001. Specifically we sorted the primary earners of the years 1984, 1990 and 1996 into seven cohorts and divided them within each cohort into six income classes. Then we compiled for each cohort and income class the respective income classes of its members in the surveys of the years 1989, 1995 and 2001 in order to calculate the age-specific transition matrices.

Table 1 reports the calibrated benchmark equilibria for rational consumers with stochastic and non-stochastic income. Both equilibria feature a consumption tax rate of 17 percent, progressive income taxes, borrowing constraints and lifespan uncertainty. The model with stochastic income is simulated as a closed economy in order to get the values of Table 1. Consequently, the interest rate is endogenous and the trade balance is zero. In Table 3 nearly all simulations take place in a small open economy, but the interest rate is always like in Table 1. In the model without income uncertainty we omit intragenerational heterogeneity and apply the productivity profile of the median income class. In order to calibrate a similar initial equilibrium, we keep the interest rate from the respective

\footnotetext{
${ }^{6}$ In Germany this allowance is currently $3000 €$ for nominal interest income, but $6000 €$ if the source of capital income are dividends.
} 
stochastic income model constant and assume a small open economy. In addition, we reduce the share of married couples in order to finance the same level of public goods as in the uncertain income model. Consequently, the average income tax rate is higher with non-stochastic income.

Table 1: The initial equilibrium (rational consumers)

\begin{tabular}{lrr}
\hline & $\begin{array}{r}\text { Stochastic } \\
\text { income }\end{array}$ & $\begin{array}{r}\text { Non-stochastic } \\
\text { income }\end{array}$ \\
\hline Pension benefits (\% of GDP) & 13.2 & 13.7 \\
Pension contribution rate (in \%) & 19.5 & 19.5 \\
Tax revenues (in \% of GDP) & 20.1 & 20.1 \\
Average income tax rate (in \%) & 7.8 & 10.3 \\
Interest rate p.a. (in \%) & 3.4 & 3.4 \\
Bequest (in \% of GDP) & 4.1 & 1.4 \\
Capital-output ratio & 2.9 & 2.9 \\
Gini index net income & 0.292 & - \\
Gini index wealth & 0.519 & - \\
Borrowing constraints (in \%) & & \\
age 20-24 & 20.0 & 100 \\
age 25-29 & 7.5 & 100 \\
age 30-34 & 5.8 & 100 \\
\hline
\end{tabular}

Note that in the uncertain income model the lowest two productivity classes of the youngest cohort would like to borrow because they expect a higher productivity (and therefore income) in the future. For older cohorts, the fraction of liquidity constraint agents decreases sharply. After age 35 we hardly observe liquidity constraints. Since the need for precautionary savings vanishes with certain income, representative agents in the young cohorts would like to consume more compared to the uncertain income case. Consequently, they hit their borrowing restrictions. Bequests decrease and the small open economy experiences capital inflows. The consumption to output ratio decreases and the reduced consumption tax revenues have to be balanced by higher income tax revenues. We do not report the respective equilibria for hyperbolic consumers since they are very similar. Of course, hyperbolic consumers would like to consume more when they are young compared to rational consumers. Consequently, borrowing constraints are more binding for them and the share of constrained consumers in the youngest cohorts increases to 40 and 15.1 percent respectively. In addition, the bequest share of GDP is reduced to 3.9 percent.

This should suffice to explain our calibration and initial equilibrium. Next we turn to the 
policy reforms and their risk-sharing and efficiency implications.

\section{Simulation results}

This section compares the macroeconomic and welfare consequences if the existing pay-asyou-go financed pension system is phased out and substituted by private savings. Since we don't want to hurt existing elderly and already retired agents, we simply change equation (11) to

$$
e p_{j}=e p_{j-1}(1+\bar{r})
$$

Consequently, individuals will keep their existing earning points, but they will not accumulate additional ones in the future. We assume that the existing pension claims are still financed by contributions on labor income. However, in order to smooth the burden across current and existing generations we compute a time-invariant payroll tax rate according to ${ }^{7}$

$$
\tau=\frac{\sum_{t=1}^{\infty} P B_{t}(1+r)^{1-t}}{\sum_{t=1}^{\infty} P C_{t}(1+r)^{1-t}} .
$$

Since with this payroll tax rate the budget of the pension system is not balanced in every period, pension debt $B_{P}$ develops as ${ }^{8}$

$$
B_{P, t+1}=(1+r) B_{P, t}+P B_{t}-\tau P C_{t}
$$

with $B_{P, 0}=B_{P, 1}=0$.

Similarly, for the general government budget we compute a time-invariant consumption tax rate $\tau_{c}$ that balances the intertemporal government budget and endogenizes the debt level in each period, i.e.

$$
\tau_{c}=\frac{B_{G, 1}+\sum_{t=1}^{\infty}\left[G_{t}-T_{k, t}-T_{y, t}\right](1+r)^{1-t}}{\sum_{t=1}^{\infty} C_{t}(1+r)^{1-t}},
$$

and

$$
B_{G, t+1}=B_{G, t}(1+r)+G_{t}-T_{y, t}-\tau_{c} C_{t}-T_{k, t} .
$$

Before the numerical results of the simulations are presented, we first explain the computation of the welfare changes.

\footnotetext{
${ }^{7}$ In the closed economy $(1+r)^{1-t}$ has to be replaced with $\Pi_{k=1}^{t}\left(1+r_{k}\right)^{-1}$.

${ }^{8}$ Of course, pension debt has to be included in the capital market equation (18) above.
} 


\subsection{Experimental design and social welfare}

The welfare criterion we use to assess this reform is ex-ante expected utility of an agent, before the productivity level is revealed (i.e. looking upon her life behind the Rawlsian veil of ignorance). For an agent who enters the labor market the expected utility is computed from

$$
V=\left[\int_{E_{j}} V\left(z_{1}\right)^{1-\eta} d X\left(z_{1}\right)\right]^{\frac{1}{1-\eta}} .
$$

From that point of view one has some desire for redistribution, which provides insurance for being born as a low-productivity type. Following Auerbach and Kotlikoff $(1987,87)$ we compute the proportional increase in consumption and leisure $(W)$ which would make an agent in the baseline scenario as well off as in the reform scenario. If the expected utility level after the reform is $\hat{V}$ and the expected utility level on the baseline path is $\bar{V}$, the necessary increase (decrease) in percent of initial resources is computed from

$$
W=\left[\left(\frac{\hat{V}}{\bar{V}}\right)-1\right] \times 100 .
$$

Consequently, a value of $W=1.0$ indicates that this agent would need one percent more resources in the baseline scenario to attain expected utility $\hat{V}$.

In order to asses the aggregate efficiency consequences, we introduce a Lump-Sum Redistribution Authority (LSRA) in the spirit of Auerbach and Kotlikoff $(1987,65 f$.) as well as Nishiyama and Smetters (2005a, 2005b) or Fehr and Habermann (2005). The LSRA pays a lump-sum transfer (or levies a lump-sum tax) to each living household in the first period of the transition to bring their expected utility level back to the level of the initial equilibrium. Since utility depends on age and state, these transfers (or taxes) have to be computed for every agent in the first year of the transition. Note that transfers differ only between the states of age $j$, earning points $e p_{j}$ and asset holdings $a_{j}$ but not between efficiencies for agents with the same $j, e p_{j}$ and $\mathrm{a}_{j}$. This is due to the fact that the reform is announced before the productivity shock is revealed. Consequently, age- $j$ agents who were alive in the initial equilibrium are compensated by the transfers $v_{j, 1}\left(z_{j}, \bar{V}\left(z_{j}\right)\right)$, which guaranties for each individual at state $z_{j}$ the initial expected utility level $\bar{V}\left(z_{j}\right)$. On the other hand, those who enter the labor market in period $t$ of the transition receive a transfer $v_{1, t}\left(V^{*}\right)$ which guaranties them an expected utility level $V^{*}$. Note that the transfers $v_{1, t}$ may differ among future cohorts but the expected utility level $V^{*}$ is identical for all. The value of the latter is chosen by requiring that the present value of all LSRA transfers 
is zero:

$$
\sum_{j=2}^{J} N_{j} \int_{A \times P \times E_{j}} v_{j, 1}\left(z_{j}, \bar{V}\left(z_{j}\right)\right) d X\left(z_{j}\right)+\sum_{t=1}^{\infty} v_{1, t}\left(V^{*}\right) N_{1}(1+r)^{1-t}=0 .
$$

With $V^{*}>\bar{V}$ (i.e. $W>0$ ), all households in period one who have lived in the previous period would be as well off as before the reform and all current and future newborn households would be strictly better off. Hence, the new policy is Pareto improving after lump-sum redistributions. With $V^{*}<\bar{V}$ (i.e. $W<0$ ), the policy reform is Pareto inferior after lump-sum redistributions.

\subsection{Stylized reform experiments}

In order to fix the economic intuition, we apply our model first to some stylized reform experiments which are intended to isolate the various economic effects which are at work. Starting point is a simulation where we replicate the "neutrality reform" experiment of Fenge (1995). The original theoretical model considers two overlapping generations and excludes the tax system. Consequently, in order to keep the implicit tax rate constant across the life cycle until retirement, we have to model a pension system where the internal interest factor is equal to the market interest rate, i.e. $\bar{r}=r$ in equations (11) and (20). In addition, we abstract from lifespan uncertainty (i.e. $\psi_{j}=1.0$ and $J=12$ ), borrowing constraints (i.e. $\underline{\mathrm{a}}=-\infty$ ) and interest taxation (i.e. $d_{s}=\infty$ ). Besides the pension system which now levies a contribution rate of 21 percent, the public sector comprises a proportional labor income tax of 10 percent (i.e. $d_{w}=0$ ), a corporate tax of 15 percent, a consumption tax of 17 percent and a public debt level which amounts to 60 percent of GDP.

The first column of Table 2 reports the resulting macroeconomic effects. In order to finance all existing pension claims accumulated in the pre-reform years, a payroll tax of 13.4 percent is necessary. The reduction of the contribution rate ( 7.6 percentage points) defines the implicit savings share, see Sinn (2000). The new payroll tax equals the previous implicit tax rate so that labor supply is not affected. However, due to the reduced pension contributions (which are still tax exempt), labor income tax revenues increase, so that public debt could be reduced. During the transition, tax revenues from public pensions decline to zero. Since the latter effect is stronger than the former, public debt has to be lower in the long run in order to keep the budget balanced. As a result of the reform, the future tax payments on pensions are now already payed during the working period. There is no gain in present value neither for the household nor for the government. In essence, some implicit government tax claims have been made explicit. At the household side, 
Table 2: Macroeconomic effects of social security

\begin{tabular}{|c|c|c|c|c|c|}
\hline \multirow[b]{3}{*}{ Consumers } & \multirow{3}{*}{$\begin{array}{l}\text { Neutrality } \\
\text { reform } \\
\text { rational }\end{array}$} & \multicolumn{4}{|c|}{ Benchmark reforms with stochastic income } \\
\hline & & \multicolumn{2}{|c|}{ proportional taxes } & \multicolumn{2}{|c|}{ progressive taxes } \\
\hline & & rational & naive & rational & naive \\
\hline \multicolumn{6}{|l|}{ Assets $^{a}$} \\
\hline $2010-14$ & 5.0 & 7.5 & 7.7 & 8.2 & 8.8 \\
\hline $2015-19$ & 10.7 & 16.2 & 16.8 & 17.9 & 19.2 \\
\hline $2025-29$ & 23.4 & 35.7 & 36.9 & 40.3 & 42.9 \\
\hline$\infty$ & 49.2 & 92.6 & 95.9 & 107.6 & 114.0 \\
\hline \multicolumn{6}{|c|}{ Capital stock/Labor supply/Output ${ }^{a}$} \\
\hline 2005-09 & 0.0 & 0.2 & 0.4 & -1.0 & -0.9 \\
\hline 2015-19 & 0.0 & 0.4 & 0.5 & -0.5 & -0.4 \\
\hline $2025-29$ & 0.0 & -0.1 & -0.1 & -0.6 & -0.8 \\
\hline$\infty$ & 0.0 & -6.3 & -6.7 & -7.2 & -7.7 \\
\hline \multicolumn{6}{|l|}{ Public debt ${ }^{b}$} \\
\hline $2010-14$ & 57.5 & 61.1 & 61.3 & 63.6 & 64.1 \\
\hline $2015-19$ & 54.6 & 61.9 & 62.4 & 65.7 & 66.6 \\
\hline $2025-29$ & 48.2 & 63.3 & 64.6 & 68.0 & 69.9 \\
\hline$\infty$ & 35.2 & 76.2 & 80.1 & 75.5 & 79.7 \\
\hline \multicolumn{6}{|c|}{ Pension debt ${ }^{b}$} \\
\hline $2010-14$ & 25.2 & 25.3 & 25.1 & 26.0 & 25.8 \\
\hline 2015-19 & 53.7 & 53.0 & 52.5 & 54.3 & 54.0 \\
\hline $2025-29$ & 117.4 & 110.0 & 109.5 & 112.1 & 111.7 \\
\hline$\infty$ & 246.3 & 220.0 & 220.4 & 223.3 & 223.9 \\
\hline \multicolumn{6}{|c|}{ Consumption tax rate ${ }^{c}$} \\
\hline $2005-$ & 0.0 & -1.0 & -1.0 & -2.6 & -2.7 \\
\hline \multicolumn{6}{|c|}{ Contribution rate ${ }^{c}$} \\
\hline $2005-$ & -7.6 & -7.5 & -7.5 & -7.4 & -7.3 \\
\hline
\end{tabular}

${ }^{a}$ Changes are reported in percentage over initial equilibrium. ${ }^{b}$ In percent of GDP.

${ }^{c}$ Changes in percentage points.

the additional income available to young working agents is saved so that assets increase throughout the transition. On the domestic capital market, the additional supply of assets is balanced by additional demand of the pension system. Since revenues from (lower) contributions are not sufficient to finance the benefits of the (still existing) retirees, the deficit is financed by debt. The first column of Table 2 shows that the existing implicit debt of the pension system amounts to roughly 250 percent of GDP. However, on the capital market the additional demand is exactly balanced by additional supply. Consequently, the equilibrium interest rate is not changed in the closed economy and international capital flows are not affected in the open economy. Note that the corporation tax does not alter the neutrality result since the capital stock is neither altered in the closed nor in the open 
economy.

Of course, since the considered policy reform exactly reproduces the neutrality result of Fenge (1995), welfare of households remains constant ${ }^{9}$. While Table 2 reports the results for the model with stochastic income and rational consumers, the described economic adjustment is almost completely identical in the model with hyperbolic consumers. On first sight one might have expected something different since social security serves as a commitment device for hyperbolic consumers. However, in a world without borrowing constraints consumers who lack the foresight to save adequately for their retirement years will simply reduce their initial debt when social security is eliminated.

Next we alter successively the different assumptions which are necessary to obtain the neutrality result in order to quantify their importance. First, we eliminate the weights for the earning points, i.e. we set $\bar{r}=0$ in order to replicate the existing German earning points system where the weights of the accumulated earning points are independent of the age. As a result, implicit tax rate is falling with rising working age, see Fehr (2000) or Fenge et al. (2006).

Figure 2: Contribution, implicit tax, and payroll tax rate

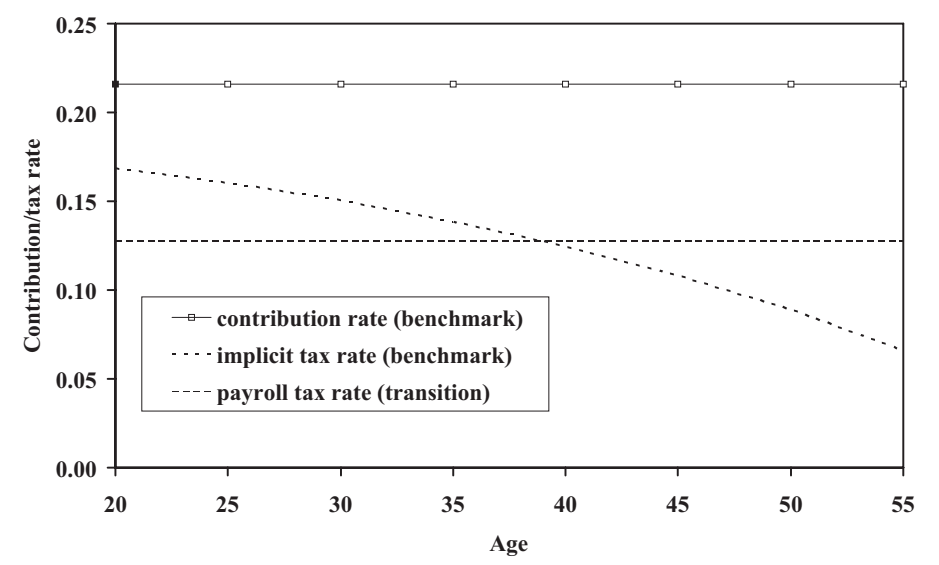

Figure 2 shows the relation between contribution rates and implicit tax rates across the life cycle. The implicit tax rate $\tilde{\tau}_{j}$ distorts labor supply and depends on the present value of the pension increase due to your actual contributions. If an age- $j$ agent earns the average income $\bar{w}$, his future pension rises by the amount of APA. His contributions in

\footnotetext{
${ }^{9}$ Apart from the pedagogic insights, this exercise also allows to examine the accuracy of the model results. In order to reduce computational time we have to limit the grid size which automatically decreases the accuracy of the results. All computed welfare changes are within the range $[-0.01 ; 0.01]$ percent of remaining resources.
} 
that period are $\tau \bar{w}$, the implicit tax rate (for $\bar{r}=0$ ) amounts to

$$
\tilde{\tau}_{j}=\tau \cdot\left[1-\frac{\left(\sum_{i=j_{R}}^{J} \frac{A P A}{(1+r)^{i-j_{R}}}\right) /(1+r)^{j_{R}-j}}{\tau \bar{w}}\right] .
$$

Whether this age-profile of marginal contribution rates is efficient depends on the ageprofile of compensated labor supply elasticities. Recently, Fenge et al. (2006) have shown that the latter decrease with age for males while females show a inversely U-shaped ageprofile of compensated labor-supply elasticities. Our model does not distinguish between genders but can distinguish between different income processes. With stochastic income, the compensated labor-supply elasticity profile rises from 0.22 (age 20-24) to 0.48 (age 55-59). The reason is that we observe at young age a precautionary motive for labor supply which vanishes with higher savings (and rising age). With non-stochastic income this precautionary motive is missing, consequently the compensated labor supply profile is almost flat and slightly falls from 0.29 (age 20-24) to 0.26 (age 55-59). Consequently, the age-independent payroll tax profile after the reform will reduce efficiency compared to the existing pay-as-you-go system in the stochastic income model and increase efficiency in the non-stochastic model. The reform experiments of simulation (1) in Table 3 exactly yield this results. However, the computed efficiency effects are rather small. This indicates that a reform of the existing point system in Germany as recently proposed by Fenge et al. (2006) has only minor efficiency consequences. Note that the reported efficiency effects are now computed by implementing LSRA transfers as described in the previous section. The reform experiments of simulation (2) introduce a capital income tax of 10 percent in the initial equilibrium. The transition to a private pension system now increases capital income tax revenues without increasing distortions but allows in turn to reduce consumption taxes. The lower intratemporal distortions increase economic efficiency slightly. In addition, as shown by Nishiyama and Smetters (2005b), the rising tax revenues from capital income improve the insurance properties of the tax system in the stochastic income model, which explains the stronger increase in the stochastic income case.

Next, the experiments of simulation (3) assume that the initial equilibrium also features borrowing constraints (i.e. $\underline{a}=0.0$ ). The transition to the private system significantly reduces these liquidity constraints due to the lower payroll tax rate. The differences in the reported efficiency effects can be explained as follows. First, young low productive agents in the stochastic income model may climb up to higher productivity profiles in the future. Therefore, they can expect higher future income levels than young agents in the certain income model where future wages only increase due to the rising age-productivity profile. Consequently, although the fraction of constrained agents is lower, liquidity constraints 
Table 3: Efficiency effects of social security*

\begin{tabular}{|c|c|c|c|}
\hline & & $\begin{array}{c}\text { Rational } \\
\text { consumers }\end{array}$ & $\begin{array}{c}\text { Naive hyperbolic } \\
\text { consumers }\end{array}$ \\
\hline Simulation & Economic environment & income & income \\
\hline
\end{tabular}

1. Stylized reform experiments with proportional taxes

\begin{tabular}{llrrrrrrr}
$(1)$ & 0.1 & 1.0 & $-\infty$ & $\infty$ & -0.09 & 0.04 & -0.08 & 0.12 \\
$(2)$ & 0.1 & 1.0 & $-\infty$ & 0.0 & 0.14 & 0.12 & 0.13 & 0.22 \\
$(3)$ & 0.1 & 1.0 & 0.0 & 0.0 & 1.07 & 0.36 & 0.34 & -0.29 \\
$(3 \mathrm{a})$ & $\eta=0.0$ & & & 1.32 & - & 0.50 & - \\
$(3 \mathrm{~b})$ & $\gamma=0.25$ & & & 3.07 & 1.24 & 1.98 & 0.04 \\
$(3 \mathrm{c})$ & $\rho=0.2$ & & & 1.43 & 0.31 & 0.52 & -0.29 \\
\hline
\end{tabular}

2. The benchmark reform with proportional taxes

$\begin{array}{lllrrrrr}(4) & 0.1 \quad<1.0 & 0.0 & 0.0 & -0.42 & -0.95 & -2.12 & -2.61 \\ (4 \mathrm{a}) & \eta=0.0 & & & 0.55 & - & -1.16 & - \\ (4 \mathrm{~b}) & \gamma=0.25 & & & 2.24 & 0.35 & 0.40 & -1.62 \\ (4 \mathrm{c}) & \rho=0.2 & & -0.56 & -0.70 & -2.52 & -2.26 \\ \text { (4d) } & \beta=0.6, \delta=1.1 & & - & - & -3.61 & -3.69\end{array}$

3. The benchmark reform with progressive taxes

\begin{tabular}{llllrrrr}
$(5)$ & $T 05 \quad<1.0 \quad 0.0$ & 1800 & 0.49 & -2.81 & -1.49 & -5.65 \\
$(5 \mathrm{a})$ & $\eta=0.0$ & & & 0.17 & - & -1.94 & - \\
$(5 \mathrm{~b})$ & $\gamma=0.25$ & & 3.00 & -1.30 & 1.20 & -4.01 \\
$(5 \mathrm{c})$ & $\rho=0.2$ & & 1.28 & -2.39 & -0.85 & -4.84 \\
$(5 \mathrm{~d})$ & $\beta=0.6, \delta=1.1$ & & - & - & -3.23 & -7.52 \\
$(5 \mathrm{e})$ & closed economy & & 0.53 & - & -1.44 & - \\
\hline
\end{tabular}

*In percent of remaining resources.

are more binding in the stochastic income model so that the reduction generates higher efficiency gains. Second, since hyperbolic consumers regret their consumption behavior at young age later in their life, borrowing constraints in combination with social security serve as a commitment device for them. The considered reform reduces this commitment technology. Consequently, the resulting consumption path is stronger distorted towards the present, inducing efficiency losses for hyperbolic consumers. As shown in the last column of Table 3, the latter effect may dominate the former in the case of non-stochastic income so that hyperbolic consumers experience even efficiency losses from the relaxation of the commitment technology.

These stylized experiments suffice to highlight the importance of borrowing constraints for the analysis of pension provision. They are not only important in their magnitude, 
but they also work in quite opposite directions for rational and hyperbolic consumers.

\subsection{Benchmark reforms with proportional and progressive taxes}

Simulation (4) introduces uncertain lifespan in the initial equilibrium (i.e. $\psi_{j}=<1.0$ ). Now our models' results could be directly compared to other studies. The second and the third column of Table 2 compare the macroeconomic effects of this reform for rational and hyperbolic consumers in the stochastic income model. Since the initial equilibria are calibrated quite similar, the effect of privatization on the payroll tax rate and the debt level of the pension system is almost identical as in the case of the neutrality reform. Individual assets increase now much stronger compared to the latter case, since savings also insure against lifespan uncertainty. Higher savings induce higher unintended bequest. This income redistribution towards future generations reduces labor supply in the long run $^{10}$. The increase in tax revenues from capital taxation is stronger than the decrease from labor taxation. Therefore tax revenues from income taxation are rising over the transition and since the consumption tax rate is time-independent (see (24)) public debt increases too.

Since private annuity markets are missing, the pay-as-you-go pension system provides an (implicit) insurance against outliving ones resources. On the other hand, the benefits of the private system are not annuitized by assumption. Consequently, the insurance provision is lost after privatization and Table 3 reports for simulation (4) significant efficiency losses for all cases considered. The case of rational consumers with non-stochastic income was already considered in Hubbard and Judd (1987). Note that hyperbolic consumers are stronger affected than rational consumers. The reason is that young hyperbolic consumers discount their very old-age consumption much less than rational consumers, see Figure 1. As a consequence, the value of the annuity provision is higher for hyperbolic consumers. Note that the parametrization of simulation (4) is very similar compared to Imrohoroğlu et al. (2003). Our results confirm their conclusions for high short-run discount rates although their calculations do not include transitional periods.

In order to reproduce the initial equilibria of Table 1, we still have to introduce the progressive tax system as described in the previous section. This is done in simulation (5) where compared to simulation (4) the tax base has changed (i.e. $d_{w}>0, d_{s}>0$ ) and the German tax rate schedule of 2005 is substituted. In order to understand the effects of the progressive tax schedule, we first discuss the labor supply effects. Here we have to distinguish between changes in the age-profile and the level of marginal income taxes. Since

\footnotetext{
${ }^{10}$ Note that in simulation (3) without bequests labor supply only falls by 0.4 percent!
} 
marginal income tax rates increase with age, the decreasing marginal contribution rate of the pay-as-you-go system flattens the age-profile of the marginal tax wedge. Some backof-the-envelope calculations show that overall marginal taxes are slightly hump-shaped and vary between 25 (at age 20-24) and 28 percent (at age 55-59) in the initial equilibrium. The introduction of the private system steepens the age-profile of the marginal tax wedge. Now agents face a marginal tax wedge of 21 percent in the initial working period which increases steadily to 33 percent at the end of working life. Consequently, labor supply is shifted toward the beginning of working life which in turn increases savings and reduces long run labor supply compared to the case with proportional taxes, see the last two columns of Table 2 .

Of course, due to the rising labor supply elasticity across the life cycle, this age-profile effect increases labor supply distortions. In addition, the rising interest income from savings increases the marginal tax rate on labor income and allows to reduce the consumption tax. This change from consumption to income taxes reduces economic efficiency as already shown in Auerbach and Kotlikoff (1987). Labor supply and tax structure effects mainly explain the efficiency losses in the case of non-stochastic income of Table 3. With stochastic income, the explanation is complicated by the implied insurance effects of the tax structure. As Nishiyama and Smetters (2005b) have recently shown, consumption tax systems provide less insurance against income shocks than progressive income tax systems and the latter effect might even outweigh the increased labor supply distortions. This reasoning also applies to our simulation. The reduction of consumption taxes improves the insurance properties of the tax system which overcompensates the increased labor supply distortions and improves economic efficiency as shown in the stochastic income case of Table 3. Hyperbolic consumers experience a stronger efficiency loss with non-stochastic income and a weaker efficiency gain with stochastic income compared to rational consumers. This is due to the fact that in both cases the rising capital income after privatization increases the marginal tax rate, so that their already excessive consumption in young age is further increased by privatization.

Although our central interest are the aggregate efficiency effects of eliminating social security, it might also be interesting to compare the intra- and intergenerational welfare effects of the considered benchmark reforms. Table 4 reports for the two benchmark reforms with rational consumers the resulting welfare effects for different cohorts in the reform year and the long run if no compensation transfers are implemented. The reported intragenerational disaggregation reflects the realized productivity level: "Poor" individuals are those 10 percent of the population with the lowest realized productivity level, "median"individuals are those 20 percent who realize the forth productivity 
level and "rich" individuals are those 20 percent of the population who realize the highest productivity level. With proportional taxes, the already retired generations are gaining slightly, while the middle-aged generations are losing and young and future generations are gaining significantly. Of course, the welfare gains for the already retired are due to the slight reduction in consumption taxes reported in Table 2. Note that there is almost no difference between income classes. The significant losses of the middle-aged are due to the fact that in the current German system the implicit tax rate falls significantly before retirement, see Figure 2. Consequently, the considered reform raises the payroll tax rates for those cohorts. Since poor individuals work more than rich ones, the former are hurt stronger than the latter. In addition, the medium generations do not receive much unintended bequests from their predecessors. However, they have to save more now in order to insure against live span uncertainty. Young and future generations mainly gain for two reasons. First, they pay lower payroll taxes after the reform since their implicit tax rate in the initial equilibrium was higher than the payroll tax rate after the reform, see again Figure 2. In addition, they also benefit from the increased unintended bequests ${ }^{11}$. Note that poor individuals realize especially strong welfare gains in the long run since their liquidity constraints are relaxed due to higher bequests and the lower payroll tax rate.

Table 4: Welfare effects of social security with rational consumers

\begin{tabular}{lrrrrrr}
\hline \multirow{2}{*}{$\begin{array}{l}\text { Age in } \\
\text { reform } \\
\text { year }\end{array}$} & \multicolumn{3}{c}{ The benchmark reform with stochastic income } \\
\cline { 2 - 7 } & \multicolumn{2}{c}{ proportional taxes } & \multicolumn{4}{c}{ progressive taxes } \\
\hline $90-94$ & 0.63 & 0.57 & 0.51 & 1.68 & 1.50 & 1.36 \\
$80-84$ & 0.61 & 0.52 & 0.45 & 1.61 & 1.42 & 1.29 \\
$60-64$ & 0.55 & 0.47 & 0.40 & 1.46 & 1.29 & 1.14 \\
$40-44$ & -3.49 & -2.69 & -1.47 & -2.93 & -2.55 & -2.32 \\
$20-24$ & 0.67 & -0.94 & -1.13 & 1.16 & -0.59 & -1.35 \\
$00-04$ & 2.66 & 1.15 & 0.85 & 3.00 & 1.36 & 0.62 \\
$\infty$ & 6.14 & 4.56 & 4.54 & 6.26 & 4.60 & 4.36 \\
\hline
\end{tabular}

${ }^{a}$ Changes are reported in percentage of initial ressources.

The right part of Table 4 reports the welfare consequences when a progressive tax is levied initially. Of course, the welfare gains for pensioners are significantly stronger now since the consumption tax rate is reduced much stronger, see Table 2. With progressive taxes, poor medium-aged individuals lose less while rich ones lose more compared to the proportional tax case. Marginal taxes increase for both types but since excess burdens

\footnotetext{
${ }^{11}$ In simulation (3) there are only slight gains for generations living in the long run!
} 
increase quadratic in tax rates, efficiency losses are higher for rich individuals.

We do not report the welfare effects for hyperbolic individuals. For retired agents they are very similar as those reported in Table 4 . On the other hand, the welfare losses of working-age agents are higher and the welfare gains of future agents are lower in the hyperbolic case. The difference reflects the higher aggregate efficiency loss of hyperbolic agents which was reported and already explained in Table 3.

\subsection{Sensitivity analysis}

In this section we report the sensitivity of our results with respect to some central preference parameters. In order to save space, we restrict our attention to aggregate efficiency effects of Table 3. In Simulation (3a) assume that consumers are completely risk neutral (i.e. $\eta=0.0$ ). In this case they will reduce their precautionary savings already in the initial equilibrium so that the borrowing constraint is more binding for poor individuals. As a consequence, the elimination of social security now induces a stronger (positive) liquidity effect compared to simulation (3). Of course, the same reasoning also applies to the precautionary motive against lifespan uncertainty. Therefore, risk neutral consumers are much better off than risk avers consumers when life span uncertainty is taken into account. On the other hand, risk neutral consumers do not need the insurance provision of the tax system. Consequently, with progressive taxes they are worse off than the risk avers consumers.

Next we return to the original assumption about risk aversion and assume that the intertemporal substitution elasticity $\gamma$ is reduced from 0.5 to 0.25 . As a consequence, the optimal consumption profile becomes flatter, so that liquidity constraints in the initial equilibrium are binding much stronger. Again, the stronger (positive) liquidity effect from privatization explains the higher efficiency gains in all cases considered.

In simulations (3c), (4c) and (5c) the intratemporal elasticity $\rho$ is reduced from 0.6 to 0.2 , which reduces the compensated elasticity of labor supply from 0.34 to 0.17 . The relevant issue for labor supply considerations is the change from falling to flat tax rates over the life cycle. Due to the labor-supply elasticity profiles for stochastic (certain) income, the reduced elasticities increase (decrease) welfare gains in simulation (3c) compared with (3). On the other hand, the reduced labor supply elasticity also dampens the ability to insure against lifespan risk. Consequently, efficiency losses with uncertain income are higher with a low labor supply elasticity. Finally, a reduced labor supply elasticity dampens the distortions from the progressive tax system. This explains the lower efficiency losses in all experiments of simulation (5c) compared to the respective ones of simulation (5). 
Next, we strengthen the present-bias of hyperbolic consumers by reducing the short-run discount factor $\beta$ from 0.75 to 0.6 while increasing the long-run discount factor $\delta$ from 1.0 to 1.1 in order to obtain the same initial capital-output ratio, see Figure 1. This parametrization is in line with İmrohoroğlu et al. (2003) and it clearly isolates our central argument. As shown in simulations (4d) and (5d), if the economy would be populated with consumers that feature a strong hyperbolic discounting, the efficiency losses from privatization of social security would be much higher. The intuition is straight forward: The stronger preferences are biased towards the presence, the more do consumers honor social security as a commitment device against these distorted believes. Additional, strong hyperbolic consumers discount their very old age consumption less than hyperbolic consumers, see Figure 1. Therefore, they suffer more from abolishing annuities. If we apply the strong hyperbolic parametrization to "sophisticated" consumers, the value function exhibits different local maxima. Consequently, it would require more sophisticated techniques to obtain the optimum ${ }^{12}$.

If we adjust in the case of proportional taxes the government budget by payroll taxes instead of consumption taxes, our results would also hardly be affected. Of course this is due to the fact that in this case the consumption tax rate adjusts only slightly. Finally, it is also possible to eliminate social security in a closed economy since the initial equilibrium with progressive taxes of Table 1 is calibrated as a closed economy. As shown in simulation (5e) of Table 3 this assumption has almost no impact on the results. The reason is, of course, that most of the increase in assets reported in Table 2 is balanced by rising public and pension debt.

\section{Discussion}

The results of this paper strongly suggest that social security plays a positiv role if Germany is populated by hyperbolic consumers, while the results are mixed for rational consumers. For our central parametrization social security induces an overall welfare gain which amounts to roughly 1.5 percent of aggregate resources in the hyperbolic model and a welfare loss of about 0.5 percent of resources in the model with rational consumers. Our simulations also identify and isolate quantitatively the central effects which are at work. Social security provides an insurance against lifespan uncertainty and serves as a commitment device for hyperbolic consumers, at the same time it also increases the borrowing

\footnotetext{
${ }^{12}$ Laibson et al. (1998) who simulate hyperbolic discounting with sophisticated believes report that they observe stongly nonmonotonic and noncontinuous consumption functions for low values of $\beta$.
} 
constraints for young households. It's important to note that social security induces only small distortions of life-cycle labor supply. Consequently, the immediate policy implications for Germany are twofold. First, reform proposals such as Fenge et al. (2006) which intend to alter the weights of the German point system find only weak support. Second, proposals which call for the introduction of a basic allowance for contributions find a strong support, since such reforms reduce initial borrowing constraints.

As we consider an intragenerationally fair social security system which does not redistribute within generations, there is no insurance provision against income uncertainty. However, Fehr and Habermann (2005) have shown in a companion paper that a more progressive social security system would increase aggregate efficiency in Germany. If our initial social security system reflects the optimal progressivity as suggested by Fehr and Habermann (2005), the elimination would yield an overall efficiency loss of 2.8 percent of aggregate resources even for rational consumers with uncertain income. This finding indicates that social security might play an even stronger positive role in countries such as the US or UK where it clearly redistributes within generations. This supports the results of Nishiyama and Smetters (2005a) who found aggregate efficiency losses when they scaled down the US social security system. On the other hand, our results are in contrast with most of the previous literature which either compares only steady states or compensates transitional generations not adequately.

\section{Appendix A: Computational Method}

In order to compute a solution we have to discretize the state space. The state of a household is determined by $z_{j}=\left(j, \mathrm{a}_{j}, e p_{j}, e_{j}\right) \in \mathcal{J} \times A \times P \times E_{j}$ where $\mathcal{J}=\{1, \ldots, J\}, A=$ $\left\{\mathrm{a}^{1}, \ldots, \mathrm{a}^{n_{A}}\right\}, P=\left\{e p^{1}, \ldots, e p^{n_{P}}\right\}$ and $E_{j}=\left\{e_{j}^{1}, \ldots, e_{j}^{n_{E}}\right\}$ are discrete sets. In this paper we use $J=16, n_{A}=60, n_{P}=15$ and $n_{E}=6$. The initial values for efficiencies are: $\xi\left(1,0,0, e_{1}^{1}\right)=\xi\left(1,0,0, e_{1}^{2}\right)=0.1$ and $\xi\left(1,0,0, e_{1}^{3}\right)=\cdots=\xi\left(1,0,0, e_{1}^{6}\right)=0.2$.

For all these possible states $z_{j}$ we compute the optimal decision of households from (5). The pension grid is equidistant while the asset grid has increasing intervals between two grid points. This is useful since the value function is heavily curved for low values of assets. Since $u\left(c_{j}, \ell_{j}\right)$ is not differentiable in every $\left(c_{j}, \ell_{j}\right)$ and $V\left(z_{j+1}\right)$ is only known in a discrete set of points $z_{j+1} \in\{j+1\} \times A \times P \times E_{j}$, this maximization problem can not be solved analytically. Therefore we have to use the following numerical maximization and interpolation algorithms to compute households optimal decision:

1. Compute (5) in age $J$ for all possible $z_{J}$. Notice that $V\left(z_{J+1}\right)=0$ and households are not allowed to work anymore. Hence, in the optimum households should consume everything they have. 
2. For $j=J-1, \ldots, 1$ :

Find (5) for all possible $z_{j}$ by using Powell's algorithm (Press et. al., 2001, 406ff.). Since this algorithm requires a continuous function, we have to interpolate $V\left(z_{j+1}\right)$. Having computed the data $V\left(z_{j+1}\right)$ for all $z_{j+1} \in\{j+1\} \times A \times P \times E_{j}$ in the last step, we can now find a function $s p_{j+1}$ which satisfies the interpolation conditions

$$
s p_{j+1}\left(j+1, a_{j+1}^{l}, e p_{j+1}^{m}\right)=E V\left(z_{j+1}\right)
$$

for all $l=1, \ldots, n_{A}$ and $m=1, \ldots, n_{P}$. In this paper we use multidimensional cubic spline interpolation, i.e. $s_{j}: \mathcal{S}_{3} \times \mathcal{S}_{3} \rightarrow \mathbb{R}$, whereas $\mathcal{S}_{3}$ is the space of all one-dimensional, twice continuously differentiable, piecewise third-order polynomial functions and $\mathcal{S}_{3} \times \mathcal{S}_{3}$ its tensor product (cf. Judd $(1998,225 \mathrm{ff}$.)). Further information is available upon request. The multidimensional cubic spline interpolation allows a reduction of $n_{A}$ and $n_{P}$ to only a few points with the same accuracy as multidimensional line interpolation. Since spline interpolation is problematic if assets can be negative, we need multidimensional line interpolation in this cases and set $n_{A}=60$. For all simulations without negative assets $n_{A}=12$ would not change results in an perceivable way.

\section{Appendix B: Sensitivity analysis regarding $J, n_{A}$ and $n_{P}$}

If we increase the number of periods $J$ in order to reduce the period length, we would have to recalculate the age- and productivity dependent distribution scheme $\Gamma\left(j, e_{j}\right)$ as well as the Markov transition matrix. To avoid this time demanding recalculation, we consider for these sensitivity calculations only the certain income case and assume that only agents at the age of $j_{R}-1$ receive bequests. Given these assumptions, the efficiency gain of reform (5) for rational agents changes from -2.81 (as reported in Table 3) to -2.83. This result is computed with $n_{A}=60$ and $n_{P}=15$. If we lowered $n_{A}=12$ and $n_{P}=5$ we obtained -2.80. It is obvious that welfare effects would not change significantly if the grid would be finer than $n_{A}=60$ and $n_{P}=15$.

Next, we change $J$ keeping $n_{A}$ constant at 20 and $n_{P}$ at 15 . From our assumptions made above, the efficiency gain of reform (4) for rational agents changes from -0.95 (in Table 3 ) to -1.03. If now $J$ is increased from 16 to 40 we obtain -0.99. Similar changes can be reported for other parameter combinations. Therefore, we are very optimistic that our central qualitative results would not change if we reduce the models' period length to a year in the uncertainty model. 


\section{Appendix C: Markov transition matrices}

\section{Age dependent Markov transition matrices}

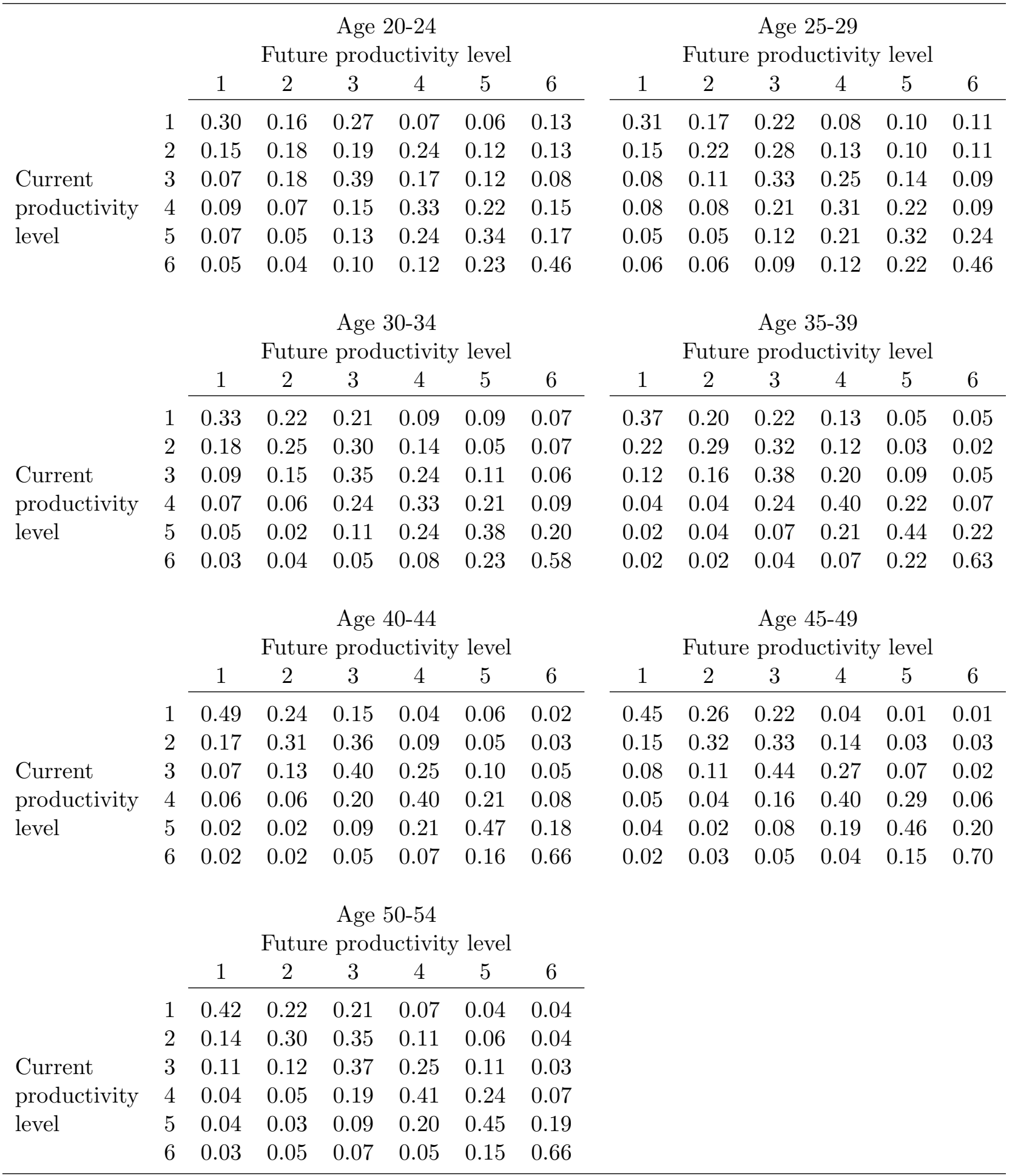

Source: Authors' own calculations from 1984-2001 SOEP data 


\section{References}

Angeletos, G.M., D. Laibson, A. Repetto, J. Tobacman and S. Weinberg (2001): The hyperbolic consumption model: Calibration, simulation, and empirical evaluation, Journal of Economic Perspectives 15 (3), 47-68.

Auerbach, A.J. and L.J. Kotlikoff (1987): Dynamic fiscal policy, Cambridge University Press, Cambridge.

Breyer, F. (1989): On the intergenerational Pareto efficiency of pay-as-you-go financed pension systems, Journal of Institutional and Theoretical Economics 145, 643-658.

Breyer, F. and M. Straub (1993): Welfare effects of unfunded pension systems when labor supply is endogenous, Journal of Public Economics 50, 77-91.

Bomsdorf, E. (2003): Sterbewahrscheinlichkeiten der Periodensterbetafeln für die Jahre 2000 bis 2100, Eul Verlag, Köln.

Cecchetti, S.G., P.S. Lam and N.C. Mark (2000): Asset pricing with distorted beliefs: Are equity returns too good to be true? American Economic Review 90, 787-805.

Conesa, J. and D. Krueger (1999): Social security reform with heterogeneous agents, Review of Economic Dynamics 2, 757-795.

Corneo, G. and M. Marquard (2000): Public pensions, unemployment insurance, and growth, Journal of Public Economics 75, 293-311.

Demmel, R. and C. Keuschnigg (2000): Funded pensions and unemployment, Finanzarchiv 57 (1), 22-38.

Epstein, L.G. and S.E. Zin (1991): Substitution, risk aversion, and the temporal behavior of consumption and asset returns: An empirical analysis, Journal of Political Economy 99, 263-286.

Fehr, H. (1999): Welfare effects of dynamic tax reforms, Mohr Siebeck, Tuebingen.

Fehr, H. (2000): Pension reform during the demographic transition, Scandinavian Journal of Economics 102, 419-443.

Fehr, H. and C. Habermann (2005): Risk sharing and efficiency implications of progressive pension arrangements, CESifo Working Paper No. 1568, Munich. 
Feldstein, M. (1997): The costs and benefits of going from low inflation to price stability, in: C. Romer and D. Romer (eds.), Reducing inflation, University of Chicago Press, Chicago and London, 123-156.

Feldstein, M., ed. (1998): Privatizing social security, The University of Chicago Press, Chicago and London.

Fenge, R. (1995): Pareto-efficiency of the pay-as-you-go pension system with intragenerational fairness, Finanzarchiv 52, 357-363.

Fenge, R., S. Übelmesser and M. Werding (2006): On the optimal timing of implicit social security taxes over the life cycle, Finanzarchiv 62, 68-107.

Fuster, L., A. İmrohoroğlu, and S. İmrohoroğlu (2003): A welfare analysis of social security in a dynastic framework, International Economic Review 44 (4), 1247-1274.

Fuster, L., A. İmrohoroğlu, and S. İmrohoroğlu (2006): Elimination of social security in a dynastic framework, forthcoming in: Review of Economic Studies.

Geanakoplos, J., O.S. Mitchell and S.P. Zeldes (1998): Would a privatized social security system really pay a higher rate of return? in: D. Arnold, M. Graetz and A. Mundell (eds.), Framing the social security debate: Values, politics and economics, Brookings Institution Press, Washington, 137-157.

Homburg, S. (1990): The efficiency of unfunded pension schemes, Journal of Institutional and Theoretical Economics 146, 640-647.

Huang, H., S. İmrohoroğlu, and T. Sargent (1997): Two Computations to Fund Social Security, Macroeconomic Dynamics 1, 7-44.

Hubbard, G. and K. Judd (1987): Social security and individual welfare: Precautionary saving, borrowing constraints and the payroll tax, American Economic Review 7\%, 630-646.

İmrohoroğlu, A., S. İmrohoroğlu and D.H. Joines (1995): A life-cycle analysis of social security, Economic Theory 6, 83-144.

İmrohoroğlu, A., S. İmrohoroğlu and D.H. Joines (1999): Social security in an overlapping generations economy with land, Review of Economic Dynamics 2, 638-665.

İmrohoroğlu, A., S. İmrohoroğlu and D.H. Joines (2003): Time-inconsistent preferences and social security, Quarterly Journal of Economics CXVIII, 745-784. 
Judd, K.L. (1998): Numerical Methods in Economics, The MIT Press, Cambridge.

Kotlikoff, L. (1996): Privatizing social security: How it works and why it matters, in: J. Poterba, ed., Tax Policy and the Economy 10, 1-32.

Laibson, D.I., A. Repetto and J. Tobacman (1998): Self-control and saving for retirement, Brookings Papers on Economic Activity 1, 91-196.

Nishiyama, S. and K. Smetters (2005a): Does social security privatization produce efficiency gains? NBER Working Paper 11622, Cambridge.

Nishiyama, S. and K. Smetters (2005b): Consumption taxes and economic efficiency with idiosyncratic wage shocks, Journal of Political Economy 113, 1088-1115.

O'Donoghue and Rabin (1999): Doing it now or later, American Economic Review 89, 103-124.

Press, W.H. , S.A. Teukolsky, W.T. Vetterling and B.P. Flannery (2001): Numerical Recipes in Fortran 7\%, Volume 1 of Fortran Numerical Recipes, Cambridge University Press, Cambridge.

Sinn, H.W. (2000): Why a funded pension system is useful and why it is not useful, International Tax and Public Finance 7, 389-410.

Strotz, R.H. (1956): Myopia and inconsistency in dynamic utility maximization, Review of Economic Studies 23, 165-180. 